PONTIFÍCIA UNIVERSIDADE CATÓLICA DO RIO DE JANEIRO

Empreendedorismo no Esporte Amador de Praia Rodrigo Noronha Chaves

Trabalho de Conclusão de CuRso

Centro de ciências Sociais - CCS

DePARTAMENTO dE AdMINISTRAÇÃO

Graduação em Administração de Empresas 
Rodrigo Noronha Chaves

\section{Empreendedorismo no Esporte Amador de Praia}

\section{Trabalho de Conclusão de Curso}

Trabalho de Conclusão de Curso, apresentado ao programa de graduação em Administração da PUC-Rio como requisito parcial para a obtenção do título de graduação em Administração.

Orientador (a): Lygia Alessandra Magalhães Magacho

Rio de Janeiro, junho de 2019. 


\section{Agradecimentos}

Em primeiro lugar gostaria de agradecer a minha família, que sempre esteve do meu lado independente do momento. Minha mãe Julieta, meu pai José Roberto e minha irmã Natália e meus demais familiares.

Gostaria de agradecer a Lygia, minha orientadora, que apesar de todos os contratempos sempre foi solícita não só como minha orientadora, mas em todas as aulas em que eu tive o prazer de ser seu aluno.

Gostaria de agradecer a minha psicóloga Vera, que também foi fundamental para que eu mantivesse minha cabeça no lugar durante mais de 12 anos.

Gostaria de agradecer a todos os meus amigos, sem exceção.

Gostaria de agradecer a todos os professores, funcionários que ajudaram na minha caminhada enquanto aluno.

Gostaria de agradecer a todos os entrevistados, que foram extremamente atenciosos e solícitos.

Gostaria de agradecer a Pontifícia Universidade Católica do Rio de Janeiro por me oferecer toda estrutura.

Gostaria de agradecer à empresa na qual eu trabalho hoje, a Stone Pagamentos S.A.

E por fim, gostaria de agradecer a todos os envolvidos na minha constante evolução enquanto pessoa, tenho muito orgulho de quem eu me tornei até hoje. 


\section{Resumo}

Chaves, Rodrigo. Empreendedorismo no Esporte Amador. Rio de Janeiro, 2019. Número de páginas: 38. Trabalho de conclusão de curso. Departamento de Administração. Pontifícia Universidade Católica do Rio de Janeiro.

O trabalho teve como objetivo identificar e analisar as principais características do perfil do empreendedor e a maneira como estruturam seus empreendimentos na área do esporte amador. Através de pesquisas bibliográficas, documentais e entrevistas feitas com empreendedores de esportes amadores praticados ao ar livre, especificamente na praia, foi possível avaliar de forma holística a gestão desses empreendimentos.

Palavras-chave: Empreendedorismo; Esporte Amador; Perfil do Empreendedor; Modelo de Negócios.

\section{Abstract}

Chaves, Rodrigo. Entrepreneurship in Amateur Sports. Rio de Janeiro, 2019. Number of pages: 38. Trabalho de conclusão de curso. Departamento de Administração. Pontifícia Universidade Católica do Rio de Janeiro.

The study has the objective to identify and analyze the main features profile of the entrepreneur and how they structure their business in the amateur sports. Through bibliographical research, documentaries and interviews with amateur sports entrepreneurs, it was possible to evaluate in a holistic way the management of these enterprises.

Key words: Entrepreneurship; Amateur Sport; Profile of the Entrepreneur; Business Model. 


\section{Sumário}

1 Introdução 6

1.1. Objetivo Final 8

1.2. Delimitação do Tema

1.3. Relevância 8

2 Referencial Teórico 10

$\begin{array}{ll}2.1 \text { Empreendedorismo } & 10\end{array}$

2.1.1 Empreendedorismo no Esporte 10

$\begin{array}{ll}\text { 2.1.3 Perfil do Empreendedor } & 11\end{array}$

$\begin{array}{ll}2.2 \text { Modelo de Negócios } & 14\end{array}$

2.2.1 BMG - Canvas $\quad 15$

3 Metodologia de Pesquisa $\quad 17$

$\begin{array}{ll}3.1 \text { Tipo de Pesquisa } & 19\end{array}$

$\begin{array}{ll}3.2 \text { Procedimento de Pesquisa } & 19\end{array}$

3.3 Instrumento de Coleta de Dados 20

3.4 Tratamento e Análise de Dados $\quad 21$

3.5 Limitações para o Estudo $\quad 21$

4 Análise e Resultados $\quad 22$

4.1Oportunidade e Necessidade $\quad 23$

4.2 Inovação e Entusiasmo 23

4.3 Riscos e Erros $\quad 24$

4.4 Benefícios para a Sociedade $\quad 25$

4.5 Inspiração 26

$\begin{array}{ll}4.6 \text { Desafios } & 27\end{array}$

4.7 Modelo de Negócios $\quad 28$

$\begin{array}{ll}\text { 4.7.1 BMG - Canvas } & 29\end{array}$

5 Conclusão 33

6 Bibliografia $\quad 35$

7 Apêndice 1 - Roteiro de Entrevista 39 


\section{Introdução}

O estudo a seguir procura identificar como os empreendedores estruturam seus negócios no esporte amador de praia no Rio de Janeiro.

Amador, em seu sentido mais comum, significa aquele que ama o que faz, aplicado ao esporte, é aquele que pratica determinada modalidade pelo amor, pelo prazer ou por busca de um estilo de vida mais saudável.

"No Brasil, o crescimento econômico decorrente da prática esportiva e as atividades de produção, comércio e serviços relacionadas ao esporte em geral atingiram em 2005, cerca de 15,6 bilhões de dólares, equivalente a 1,95\% do PIB brasileiro naquele ano, que foi 798 bilhões de dólares. Os investimentos privados representaram 1,75\% e os investimentos do setor público somaram o outro 0,20\%. Para se ter uma noção do crescimento econômico do esporte no Brasil, de 1995 a 2005, o PIB brasileiro cresceu, em média, 3,2\% ao ano, enquanto o PIB do esporte nacional cresceu 10,86\% anualmente (IIM, 2006, com dados fornecidos pelo IBGE). Enfim, o esporte é um excelente negócio." (Paulo Henrique Azevedo, 2009).

O Empreendedorismo Esportivo vem se desenvolvendo devido, em parte, aos grandes eventos internacionais sediados no Brasil nos últimos anos: Copa do Mundo em 2014, Olimpíadas em 2016 e Paraolimpíadas em 2016. O setor apresenta grande potencial, pois possui um mercado consolidado, entretanto, pouco explorado no que diz respeito à gestão profissional. Outro principal motivo pelo qual cresce o número de empreendedores no esporte é o fato de serem ofertados diversos cursos de gestão esportiva o que proporciona o ensino de práticas de gestão no esporte, encontro de interessados por esse tipo de negócio.

Apesar dos incentivos para uma vida mais saudável das últimas gerações, o brasileiro ainda encontra dificuldade. Ao contrário do que se pode imaginar, o estado do Rio de Janeiro é o que possui o menor número de praticantes de esporte do país, com apenas $18 \%$ da população e, ou seja, é um mercado com potencial de crescimento (CBN Rádio Globo, 2017). A falta de infraestrutura é uma das razões desse baixo percentual, já que o carioca passa boa parte de seu dia se locomovendo de casa para o trabalho e vice-versa. Esportes coletivos que necessitam um número maior de praticantes simultâneos, como futebol, basquete e vôlei, o que dificulta na vida moderna e corrida a possibilidade de agendar um horário que todos possam, 
fazem com que as pessoas optem, muitas vezes, por academias. Segundo o site da Exame (2019), no Brasil existem mais de 34.500 academias, totalizando 9,6 milhões de clientes no ano de 2018.

Entretanto, alguns novos esportes têm surgido e conquistado praticantes, como é o caso do beach tennis, que chegou ao Brasil em 2008 e em 2018 já contava com mais de 60 mil praticantes, segundo o site da FTP (Federação Paulista de Tênis), além disso, segundo Roberto Fadul (2018), diretor de beach tennis da Federação Paulista de Tênis, o aumento anual de praticantes é de 150 a 200\%. O beach tennis é apenas um exemplo de como o cidadão brasileiro tem aberto o leque de opções a respeito dos esportes os quais pratica. Alguns outros esportes que vem se desenvolvendo e tem crescido o número de praticantes são: o futevôlei e o vôlei de praia, que apesar de serem esportes naturalmente praticados em praias, têm sido adaptados para serem praticados em outros ambientes, como clubes e centros de treinamento. (UOL, 2018)

Esportes individuais como o ciclismo amador também têm ganhado notoriedade no cenário brasileiro. Mangaratiba, no Rio de Janeiro, recebeu o Circuito Mundial de Ciclismo amador, em 2019, no qual cerca de mil atletas, de diversas nacionalidades participaram provando mais uma vez que o esporte amador consegue atrair praticantes e com isso tornar-se rentável, além de movimentar a economia local. (Lance!, 2019)

O Poker também é um esporte que vem se desenvolvendo no Brasil, segundo a Confederação Brasileira de Texas Hold'em, em 2016, nosso país contava com 7 milhões de praticantes. (Gamesbras, 2017) Uma modalidade que até então sofria preconceito por ser considerado um "jogo de azar", mas que tem se mostrado um jogo de estratégia e gerado novos negócios.

A partir dos dados informados anteriormente, enxerga-se no esporte amador potencial de desenvolvimento de novos negócios e a possibilidade de empreender.

O que nos leva a seguinte pergunta de pesquisa: como são os perfis desses empreendedores e quais modelos de negócio utilizam?

\subsection{Objetivo Final}

O objetivo final deste trabalho é compreender o perfil do empreendedor e o modelo de negócios de empreendimentos do esporte amador. 


\subsection{Delimitação do Tema}

O estudo em questão delimita-se a analisar o perfil do empreendedor e o modelo de negócios de empreendimentos do esporte amador de praia.

Nesse trabalho foram estudados empreendimentos do esporte amador, localizados na cidade do Rio de Janeiro, em específico os esportes desenvolvidos na Praia de Copacabana e Ipanema.

O estudo não pretende abordar profundamente o nível de sucesso dos empreendedores estudados e as trajetórias empreendedoras dos entrevistados. Não se pretende tratar da questão da viabilidade financeira dos negócios estudados, e tampouco da especificidade de cada esporte.

\subsection{Relevância}

O estudo em questão possui relevância para estudantes de administração, empreendedores, futuros empresários, pesquisadores da área, e principalmente, para pessoas empreendedoras que buscam empreender seus negócios na área do esporte amador.

Os resultados desta pesquisa podem se mostrar interessantes para o crescimento dos empreendimentos voltados aos esportes amadores, fazendo com que reconheçam o potencial de geração de negócios neste mercado. O crescimento deste mercado influencia a economia da região, bem como estimula a prática de esportes e a qualidade de vida, podendo ser útil para estimular o empreendedorismo no esporte amador em outras regiões do país.

Os conceitos e as teorias estudadas servem de base para a criação de novos empreendimentos na área do esporte e do esporte amador, e instiga os profissionais da área esportiva a empreenderem através da identificação das oportunidades do mercado. 


\section{Referencial Teórico}

\subsection{Empreendedorismo}

De acordo com Dornelas (2003), empreendedorismo significa fazer algo novo, diferente, mudar a situação atual e buscar, novas oportunidades de negócio, tendo como foco a inovação e a criação de valor.

Dornelas (2008) afirma ainda, que empreendedor é aquele que detecta uma oportunidade e cria um negócio para capitalizar sobre ela, assumindo riscos calculados. O empreendedor é a pessoa que inicia e/ ou opera um negócio para realizar uma ideia ou projeto pessoal assumindo riscos e responsabilidades e inovando continuamente. Corroborando com esses dados, o brasileiro tem se mostrado com um perfil cada vez mais empreendedor, segundo pesquisa realizada pelo Global Entrepreneurship Monitor (GEM), realizada em 2019, o Brasil chegou a 38\% na TTE (Taxa de Empreendedorismo Total), no qual cerca de 52 milhões de brasileiros possuem um próprio negócio.

Segundo pesquisas do SEBRAE (2007), hoje os empreendedores não se limitam como provedores de mercadorias ou serviços desinteressantes e que somente visam o lucro. Ao contrário, assumem riscos necessários em uma economia em crescimento, produtiva ou simplesmente por necessidade de obter renda. Dessa forma, costumam gerar empregos, movimentando a economia, seja de maneira local ou global.

Leite (2000) afirma que empreendedorismo é criar valor através de pessoas com objetivos comuns, tornando-as organizações, e com esforço coletivo para aplicar ideias de maneira criativa. Dessa maneira, são pessoas que tem a capacidade de transformar ideias em produtos e serviços, sabendo dos riscos envolvidos em empreender.

Segundo Menezes (2003) o empreendedor é o indivíduo de iniciativa que promove o empreendimento a partir de um comportamento criativo e inovador, que sabe transformar contextos, estimular a colaboração, criar relacionamentos pessoais, gerar resultados, fazendo o que gosta de fazer, com entusiasmo, dedicação, autoconfiança, otimismo e necessidade de realização. 
Segundo Dolabela (2008), o empreendedorismo não é um tema novo ou modismo, existe desde a primeira ação humana inovadora, com o objetivo de melhorar as relações do homem com os outros e com a natureza.

Empreendedorismo, segundo Schumpeter (1988), é um processo de "destruição criativa”, através da qual produtos ou métodos de produção existentes são destruídos e substituídos por novos. O processo de "destruição" do modelo tradicional de empreendedorismo no esporte e a adição da tecnologia vem transformando o segmento do esporte como um todo. Somado a isso, podemos dizer que o espírito empreendedor não é somente a coragem ou disposição para implantar um negócio. Está diretamente ligado à inovação a serviço do crescimento, à exploração de um nicho de mercado imperceptível para muitos. Seguindo por essa linha, Schumpeter (apud Dornelas 2008) afirmam que o empreendedor é aquele que destrói a ordem econômica existente pela introdução de novos produtos e serviços, pela criação de novas formas de organização ou pela exploração de novos recursos materiais. Somado a isso, o empreendedor é mais conhecido como aquele que cria novos negócios, mas pode também inovar dentro de negócios já existentes, ou seja, é possível ser empreendedor dentro das empresas já constituídas.

Por outro lado, Kizner (1973) enxerga o empreendedor como aquele que cria um equilíbrio, em meio a um ambiente turbulento e instável, mantendo-se em posição clara e objetiva, enxergando oportunidades em ambientes presentes.

Portanto, apesar de algumas abordagens com distinções, são muitas as semelhanças no que diz respeito ao que é o empreendedorismo, são eles: a inovação, a oportunidade, o risco e o impacto gerado.

\subsubsection{Empreendedorismo no Esporte}

O empreendedorismo é entendido como um processo complexo e multifacetado, reconhecendo as variáveis sociais (mobilidade social, cultura, sociedade), econômicas (incentivos de mercado, políticas públicas, capital de risco) e psicológicas como influenciadoras no ato de empreender (KETS DE VRIES, 1985; CARLAND e CARLAND, 1991; HUEFNER, HUNT e ROBINSON, 1996). Dentre as características atribuídas ao empreendedor, as mais citadas são: lócus internos de controle, necessidade de realização, propensão ao risco, criatividade, visão, alta energia, postura estratégica e autoconfiança (BROCKHAUS, 1982; HORNADAY, 1982; CARLAND et al., 1984; VESPER e GARTNER, 1997). 
As definições de empreendedorismo são associadas, com frequência, a alguma "forma de inovação ou comportamento inovador gerado por um indivíduo ou um grupo, diante da percepção e da ação sobre novas oportunidades" (MAIR, 2001 apud FEUERSCHÜTTE e GODOI, 2007, p. 03).

Desde seu início no mundo moderno, o esporte como instituição social foi organizado através de uma atividade denominada gestão (ou administração) esportiva, que surgiu da necessidade de manter tais atividades físicas regularizadas, formalizadas e legitimadas (TUBINO, 1992).

O esporte é um grande alvo de empreendedores, que enxergam em seus muitos benefícios (saúde, lazer etc.) maneiras de tornarem rentáveis seus produtos e serviços, estejam eles diretamente ou indiretamente ligados à prática do mesmo.

O estudo sobre o desenvolvimento da Indústria do Esporte ocorre por meio da análise de impacto do tema na sociedade moderna em diferentes países e no contexto global (GRAÇA FILHO \& KASZNAR, 2002; KEARNEY, 2003; MILLER, STOLDT\& COMFORT, 2002; PITTS\& STOTLAR, 2002). Assim como qualquer outro tipo de negócio, a Indústria Esportiva sofre mudanças, sobretudo na forma como é oferecida aos consumidores, e a tecnologia disponível é um fator reconhecido como fundamental para agregar valor ao serviço ofertado.

Nolasco et al. (apud DACOSTA, 2005) definem a administração esportiva ou gestão do esporte como algo que: "concerne à organização e direção racional e sistemática de atividades esportivas e físicas em geral e/ou de entidades e grupos que fazem acontecer estas atividades quer orientadas para competições de alto nível ou participação popular ocasional ou regular, e práticas de lazer e de saúde" (NOLASCO et al., apud DACOSTA, 2005, p.760).

Basicamente, o esporte amador é uma prática que sempre existiu, mas não vista como uma possível fonte de renda para muitos empreendedores, até então. A partir desse raciocínio, pode-se enxergar que, o esporte amador hoje visto como negócio, antes era praticado de maneira despretensiosa e apenas como fonte de lazer e saúde.

\subsubsection{Perfil Empreendedor}

"Um empreendedor é aquele que está disposto a carregar o risco de um novo negócio se acreditar que há uma possibilidade significativa para se obter lucro". (SWOBODA apud PAULA, 2005, p.22).

Empreendedorismo é o envolvimento de pessoas e processos que em conjunto levam a transformação de ideias em práticas e oportunidades. E a eficácia 
da implementação destas oportunidades leva a criação de negócios e ao sucesso (DORNELAS, 2008). A partir dessa teoria, não basta ter uma ideia, é preciso colocála em prática e torná-la viável.

Empreendedores são pessoas que perseguem o benefício, trabalham individual e coletivamente. São definidos como indivíduos que inovam, identificam e criam oportunidades de negócios, montam e coordenam novas combinações de recursos (MORI, 1998).

Para Dornelas (2012), o empreendedorismo é o principal fator de desenvolvimento de um país, e o principal agente é o empreendedor, que consegue eliminar barreiras comerciais e culturais, diminuindo distâncias, possibilitando globalizar e renovar os conceitos econômicos, criando, assim, novas relações de trabalho e empregos, quebrando paradigmas e gerando riquezas para a sociedade.

Levando a teoria anterior em consideração, podemos afirmar que o empreendedorismo sempre existiu e é basicamente o que faz a economia de qualquer sistema econômico rodar, o empreendedor é aquele que movimenta pessoas, ideias, organizações e, consequentemente, impacta todos ao seu redor, proporcionalmente ao tamanho do seu negócio e de sua comunidade.

Paiva Jr. et al. (2003) levaram a termo uma pesquisa em que as competências associadas aos comportamentos de dirigentes de perfil empreendedor encontradas foram: competências de oportunidade, relacionamento, conceituais, administrativas, estratégicas, comprometimento e competências de equilíbrio trabalho e vida pessoal.

Para Hisrch e Peters (2004), o empreendedorismo é o processo dinâmico de criar mais riqueza. A riqueza é criada por indivíduos, que assumem os principais riscos, em termos de patrimônio, comprometimento e tempo com a carreira. É o processo de criar algo com valor dedicando o esforço e o tempo necessários, assumindo riscos sociais, psíquicos e financeiros correspondentes e recebendo as recompensas consequentes da independência e satisfação econômica e pessoal.

Essa definição de empreendedorismo ressalta quatro vertentes básicas de ser um empreendedor, independente da área de atuação. Primeiro, que o empreendedorismo envolve o processo de criação, inovação. Segundo, exige a dedicação de tempo e de esforço necessário. Em sequência, assume os riscos indispensáveis. E por final, envolve as recompensas de ser um empreendedor, que é a independência, seguida de satisfação pessoal. Para alguns, o dinheiro é apenas o indicador do grau de sucesso (HISRCH e PETERS, 2004).

Existem dois tipos básicos de empreendedores: os que empreendem por oportunidade e os que empreendem por necessidade. Os empreendedores por 
oportunidade enxergam o que falta no mercado e as novas tendências como negócios a serem explorados, enquanto os empreendedores por necessidade têm por objetivo superar um momento difícil pelo qual estão passando (BRITO; WEVER, 2004).

Dornelas (2005) complementa afirmando que o empreendedor por oportunidade sabe onde deseja chegar, é um visionário, tem um planejamento prévio do negócio, visa ao crescimento, à geração de lucros e à criação de empresas, além disso, possui estreita relação com o desenvolvimento econômico local, regional e nacional. Por outro lado, o empreendedor por necessidade inicia o seu negócio mais por falta de opção, por estar desempregado e não ter alternativas de trabalho; na maioria das vezes cria negócios informais, sem um planejamento prévio. Por esse motivo, muitos empreendimentos por necessidade não geram desenvolvimento econômico, fracassam e agravam as estatísticas de mortalidade nos negócios. Esse tipo de empreendimento é comum em países subdesenvolvidos.

Segundo o GEM (2017), que tradicionalmente elabora um agrupamento por indicadores de empreendedorismo em diversos países no mundo as taxas de empreendedorismo segundo motivação do empreendedor, ou seja, que fatores o levaram a se envolver com atividades empreendedoras. Neste caso as taxas se dividem em empreendedorismo por oportunidade e por necessidade, Tabela 1.

Tabela 1: Motivação dos empreendedores iniciais no Brasil

\begin{tabular}{lccc}
\hline Motivaçăo & Taxas & Percentual da TEA & Estimativas \\
\hline Oportunidade & 12,1 & 59,4 & 16.313 .253 \\
Necessidade & 8,1 & 39,9 & 10.965 .755 \\
Razăo Oportunidade/ Necessidade & & 1,5 & \\
\hline
\end{tabular}

Fonte: GEM Brasil 2017

' Percentual da populaçăo de 18 a 64 anos.

2 Proporçắo sobre a TEA: A soma dos valores pode năo totalizar $100 \%$ quando houverem recusas e/ou respostas ausentes.

'Estimativas calculadas a partir de dados da populaçăo de 18 a 64 anos para o Brasil em 2017: 135,4 milhőes. Fonte: IBGE/Diretoria

de Pesquisas. Projeçắo da populaçăo do Brasil e Unidades da Federaçăo por sexo e idade para o período 2000-2030 (ano 2017).

Dolabela (1999), defende que as características empreendedoras podem ser adquiridas e desenvolvidas, portanto, há a preocupação de conhecer o perfil do empreendedor de sucesso no sentido de auxiliar o processo de identificação e de aprendizado.

Pinchot (1985, apud HIRSCH; PETERS 2004, p. 61) compara as características do Gerente e do Empreendedor, determinando características dos empreendedores:

- empreendem, pois desejam independência e identificam oportunidade de gerar dinheiro;

- buscam a orientação para sobrevivência e crescimento do negócio a 
longo prazo, entre cinco e 10 anos;

- se envolvem diretamente com a atividade;

- assumem riscos moderados;

- o status: nenhuma preocupação;

- encaram as falhas e erros de forma positiva;

- as decisões são orientadas aos seus sonhos;

- procuram servir a si e aos clientes;

- possuem história familiar de empreendedores, ou de pessoas próximas que empreenderam; e

- possuem o relacionamento como habilidade básica.

Segundo estudos da ONU (Organização das Nações Unidas), as 10 principais características de um empreendedor de sucesso são:(EMPRETEC, SEBRAE 2010)

1- Busca oportunidades e toma a iniciativa;

2- Corre riscos calculados;

3- Exige qualidade e eficiência;

4- Persistente;

5- É comprometido;

Características relativas ao planejamento:

6- Busca de informações;

7- Estabelece metas;

8- Planejamento e monitoramento sistemático;

Características relativas ao poder:

9- Persuasão e rede de contatos;

10- Independência e Autoconfiança;

\subsection{Modelo de Negócios}

Qualquer negócio exige um mínimo de organização, mesmo que em um primeiro momento ele aconteça de forma amadora, independentemente do nível de inovação que essa ideia traga consigo

Segundo Dornelas (2014), a ideia criativa, genial, singular, sem precedentes, é rara e privilégio de poucos. Esses poucos empreendedores acabam 
por mudar o rumo da história com suas criações e invenções.

Por outro lado, Dornelas (2014) afirma que há também empreendedores muito bem-sucedidos que não tiveram ideias únicas, geniais, espetaculares e, mesmo assim, fizeram acontecer. Em outras palavras: não é necessário ser "apenas" genial, mas ter muita dedicação, atitude e resiliência.

Há exemplos históricos de inovação ou invenções com os quais convivemos até os dias de hoje, como o vaso sanitário, talheres, travesseiros e até a própria cama. Sempre há variações desses produtos para comprar, mas seu conceito e função, ou finalidade, continuam os mesmos (DORNELAS, 2014). Isso se aplica também para os esportes amadores, que na sua essência nada mais é do que a prática do esporte por amor, ou seja, com inovação de uma prática que já existe há anos, pode-se oferecer um produto/serviço que agregue valor e que possa ser monetizado e que gere lucros.

Para Sobral (2008), "gestão é um processo que consiste na coordenação do trabalho dos membros da organização e na alocação dos recursos organizacionais para alcançar os objetivos de uma forma eficaz e eficiente".

A partir do raciocínio anterior, uma gestão profissional, baseada em modelos de negócio é essencial para o sucesso de uma organização, sobretudo em um mercado competitivo e homogêneo, com barreiras de entrada quase inexistentes, como é o caso do esporte amador. Sobral (2008) diz que para enfrentar esses desafios: os administradores precisam desenvolver uma nova visão para suas organizações, apostar na flexibilidade e rapidez de resposta, estar atentos à diversidade cultural, considerar ética e a responsabilidade social nas suas decisões, focalizar a estratégia na satisfação dos clientes.

\subsubsection{BMG - Canvas}

"Um Modelo de Negócios descreve a lógica de criação, entrega e captura de valor por parte de uma organização." (OSTERWALDER, 2011). Segundo o próprio autor, Alexander Osterwalder, é possível caracterizar um modelo de negócio em nove componentes, os quais permitem mostrar a lógica de como uma organização pretende gerar valor, são eles:

1) Segmentos de Clientes: define os diferentes grupos de pessoas ou organizações que uma empresa busca alcançar e servir (OSTERWALDER, PIGNEUR, 2011, p. 20). Estes são os agentes mais importantes dentro de uma empresa. 
O foco de qualquer organização deve ser seu público alvo, ofertando produtos e serviços que sejam de qualidade e satisfação as necessidades dos mesmos.

2) Proposta de Valor: refere-se ao pacote de produtos e serviços que criam valor para um segmento de clientes específico (OSTERWALDER, PIGNEUR, 2011 , p. 22). A proposta de valor é o que mais pesa na escolha de um produto/serviço

3) Canais: este componente descreve como uma empresa se comunica e alcança seus segmentos de clientes para entregar uma Proposta de Valor (OSTERWALDER, PIGNEUR, 2011, p. 26), sendo o elemento que conecta o cliente com a empresa.

4) Relacionamento com clientes: este componente descreve os tipos de relação que uma empresa estabelece com os segmentos de clientes específicos (OSTERWALDER, PIGNEUR, 2011, p. 28). Existem três possíveis motivações para o aperfeiçoamento deste relacionamento: conquista de novos clientes, retenção dos clientes atuais e ampliação das vendas como um todo.

5) Fontes de Receita: este componente representa o dinheiro que uma empresa gera a partir de cada segmento de clientes (OSTERWALDER, PIGNEUR, 2011, p. 30). É importante entender quanto que cada segmento de cliente está disposto pagar pelo valor que a empresa se propõe a gerar

6) Recursos Principais: este componente descreve os recursos mais importantes exigidos para que o Modelo de Negócio e todas as partes descritas anteriormente efetivamente funcionem (OSTERWALDER, PIGNEUR, 2011, p. 34), podendo envolver elementos físicos, financeiros, intelectuais ou humanos.

7) Atividades-Chaves: este componente descreve as ações mais importantes que uma empresa deve realizar para que seu Modelo de Negócio funcione (OSTERWALDER, PIGNEUR, 2011, p. 36). Este elemento constitui nas ações essenciais para a geração de valor ao cliente.

8) Parcerias Chaves: este componente descreve a rede de fornecedores e os parceiros que fazem o Modelo de Negócio funcionar (OSTERWALDER, PIGNEUR, 2011, p. 38). As empresas criam parcerias com o objetivo principalmente de otimizar seus modelos, reduzir riscos ou adquirir recursos.

9) Estrutura de Custo: este componente descreve todos os custos envolvidos na operação de um Modelo de Negócio (OSTERWALDER, PIGNEUR, 2011, p. 40). Nesse ponto, ressalta-se a existência de dois tipos de estruturas. De um lado, há aquelas que são direcionadas pelo custo, as quais objetivam a diminuição dos custos o máximo possível. De outro, há aquelas que são direcionadas para geração de valor, as quais se concentram na geração de valor. 
A seguir, o modelo tradicional do Canvas B.M.G:

\section{Business Model Canvas}

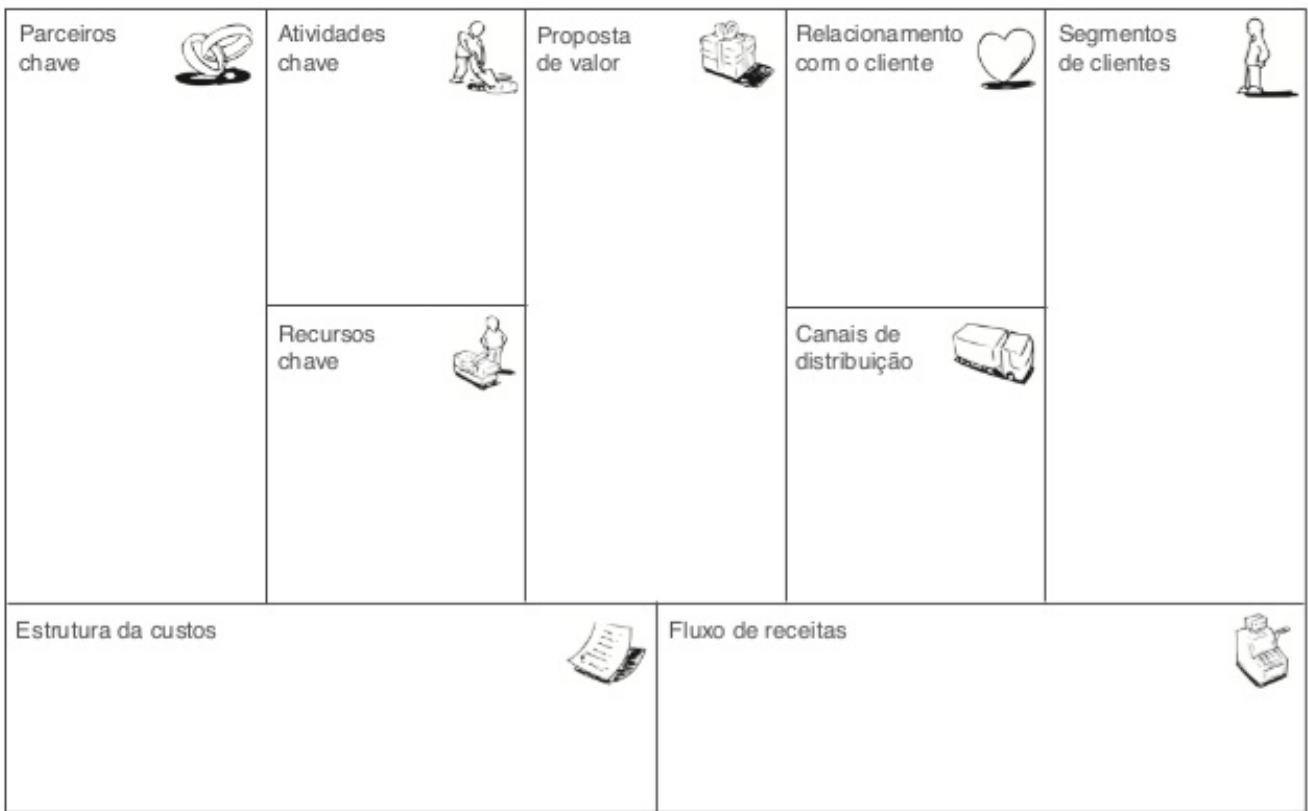

Figura 1: Modelo de Negócios Canvas (Business Model Canvas)

Fonte: OSTERWALDER, PIGNEUR (2011, p. 44) 


\section{Metodologia de Pesquisa}

\subsection{Tipo de Pesquisa}

O tipo de pesquisa utilizado foi descritivo e exploratório com empreendedores do ramo esportivo, de variadas modalidades praticadas na praia. Como afirma Gil (2008): “(...) as pesquisas exploratórias têm como principal finalidade desenvolver, esclarecer e modificar conceitos e ideias, (...) envolvem levantamento bibliográfico e documental, entrevistas não padronizadas e estudos de caso. Procedimentos de amostragem e técnicas quantitativas de coleta de dados não são costumeiramente aplicados nestas pesquisas. (...). Este tipo de pesquisa é realizado especialmente quando o tema escolhido é pouco explorado e torna-se difícil sobre ele formular hipóteses precisas e operacionalizáveis". (GIL,2008).

Dessa forma, trata-se de uma pesquisa qualitativa de forma a obter dados primários, através de entrevistas com um roteiro pré-estabelecido, mas com abertura para possíveis experiências vividas pelos entrevistados.

De acordo com Salvador (1980, apud Ribeiro 2008), a entrevista, atualmente é um instrumento ao qual os pesquisadores recorrem sempre que têm necessidade de obter dados que não podem ser encontrados em registros e fontes documentais, podendo estes serem fornecidos apenas por determinadas pessoas.

Por se tratar de esportes amadores, são dados que não são facilmente encontrados facilmente.

Os entrevistados escolhidos foram empreendedores do ramo esportivo, na esfera amadora, de variadas modalidades esportivas.

\subsection{Procedimento de Pesquisa}

Gil (1999, p. 45), conceitua pesquisa como: "procedimento racional e sistemático que tem como objetivo proporcionar respostas aos problemas que são propostos. (...) A pesquisa é desenvolvida mediante o concurso dos conhecimentos disponíveis e a utilização cuidadosa de métodos, técnicas e outros procedimento científicos (...) ao longo de um processo que envolve inúmeras fases, desde a adequada formulação do 
problema até a satisfatória apresentação dos resultados." Como dito anteriormente, o procedimento de pesquisa foram entrevistas qualitativas realizadas com empreendedores do ramo esportivo de variadas modalidades, a fim de aprofundar e obter dados primários que não podem ser encontrados com facilidade, a partir disso podemos citar Rosa e Arnoldi (2006) e Luna (1988) que referem-se à pesquisa como "uma atividade de investigação capaz de oferecer e, portanto, produzir um conhecimento novo a respeito de uma área ou de um fenômeno, sistematizando-o em relação ao que já se sabe".

A partir do que se diz acima, foi elaborado um roteiro de entrevista visando a obtenção de dados primários, embasado nos referenciais teóricos do capítulo 2. 0 roteiro consiste em descrever o perfil do empreendedor do ramo, a razão pela qual decidiram entrar no negócio, quais os benefícios que trazem para a sociedade e como estruturaram seus modelos de negócios.

\subsection{Instrumento de coleta de dados utilizados no estudo}

No capítulo 1, os dados foram colhidos a partir de livros, sites e artigos publicados. As informações foram coletadas em bibliotecas e na internet. Essa etapa consistia em trazer dados a respeito do tema e os motivos pelos quais o mesmo era relevante.

No capítulo 2, os dados foram coletados de livros, sites e artigos publicados. As informações foram coletadas em bibliotecas e na internet. Essa etapa consistia em fundamentar toda a teoria utilizada ao longo do documento, para sua validação ou não, e comparação de resultados.

As entrevistas dividiram-se entre presenciais e por telefone. O total de entrevistados foi de 10 pessoas, a maioria (6) delas foi gravada ou registrada com consentimento do entrevistado, enquanto outras (4) não gravadas a pedido dos entrevistados, porém o pesquisador utilizou suas notas realizadas durante a entrevista para coletar os dados. Foram entrevistadas 10 pessoas do gênero masculino e 1 do feminino, com idades variando entre 21 e 64 anos. Os entrevistados serão identificados apenas pelas iniciais ao longo do capítulo 4.

\subsection{Tratamento e Análise de Dados}

$O$ roteiro de entrevistas consiste em 21 perguntas fundamentadas em teorias citadas no referencial teórico, que estão listadas no Anexo 1. Ao longo da 
pesquisa, foram entrevistados 10 empreendedores no ramo do esporte amador, sendo 6 deles do futevôlei, 3 do beach soccer e 1 do futebol de onze.

A interpretação dos dados foi realizada após as entrevistas, e conforme dito anteriormente, as perguntas da entrevista foram baseadas em teorias utilizadas no capítulo 2 (Referencial teórico) e os resultados dos mesmos serão interpretados a partir dessas teorias.

\subsection{Limitações para o estudo}

O tema é novo e existem poucos autores que tratem especificamente de empreendedorismo no esporte, sendo ainda mais específico no âmbito amador. Sendo assim, o autor encontrou dificuldades para acessar bibliografias específicas sobre 0 tema.

Gil (2008) cita algumas limitações quanto à técnica da entrevista, dentre as quais podemos destacar, o fornecimento de respostas falsas, sejam elas por natureza consciente ou inconsciente, a influência das opiniões pessoais do entrevistador quanto às respostas e a inabilidade do entrevistado para responder adequadamente. Isso faz com que haja possíveis inverdades, sejam elas parciais ou totais, e há também um limite de interesse, além do limite no número de entrevistados. 


\section{Análise e Resultados}

\subsection{Oportunidade x Necessidade}

Conforme mencionado anteriormente por Dornelas (2008), o empreendedorismo é enxergar uma oportunidade em determinado nicho, a partir disso, de forma inovadora, criar valor para um público-alvo.

A maioria dos entrevistados enxergou a oportunidade de maneira repentina, sem muito planejamento prévio, vale destacar que todos já eram de alguma maneira envolvidos com o esporte por meio do qual desenvolvem seu negócio.

"Então, a gente tem uma rede aqui na rua Paula Freitas (Copacabana) desde 2011, né e em 2014 após a Copa do Mundo, é uma ideia entre amigos, a gente começou a jogar, fazer treinamentos, mas só a galera local, aí as pessoas começaram a passar aqui na rua, né, aqui no calçadão, perguntando se podiam, se era escolinha, se podiam treinar e a partir disso foi crescendo. "Citando D.C

Outro entrevistado, que inclusive fez parte de uma escolinha de beach soccer.

"Foi um dia que eu acabei vendo um jogo de uma escolinha que é da comunidade aqui perto, do Tabajara e eu acabei gostando pelo fato das crianças gostar da minha presença, de eu acompanhar elas, assim, incentivando. Aí elas gostaram muito do meu incentivo e aí acabou falando: "po, você bem que podia ser nosso treinador". Caraca, aquilo me deixou mega feliz e mais pra frente acabou que me deu a vontade mesmo dessa ideia sair do papel, sabe e acontecer. E acabou que aos pouquinhos eu fui, graças a Deus, acontecendo da minha escolinha entrando aos poucos, 1, 3, 5 e hoje 
em dia tem diversas categorias, graças a Deus". Citando P.A.

O próximo entrevistado também teve a oportunidade de maneira repentina, nas palavras de A.R:

"A ideia veio através de uma oportunidade com um grande amigo meu que jogava, né, os torneios, enfim e precisava de um professor de educação física pra poder abrir uma escolinha e aí me chamou e nós fundamos em 2014 o CT futevôlei Copacabana."

E por fim, o próximo entrevistado foi o único que não teve uma oportunidade repentina, mas que viu no cenário da época uma oportunidade para criar seu negócio, citando A.F:

"Me formei em educação física, a minha esposa estava se formando em educação física e eu sempre fui do ramo, né, desde 1982 e falei: vamos montar nosso projeto, vamos montar nossa escolinha $e$ partimos daí, desde 1996, 23 anos. “

\subsection{Inovação e Entusiasmo}

Como visto anteriormente nesse documento, o empreendedor promove o empreendimento a partir de um comportamento inovador, que gosta do que faz, conforme Sebrae (2007) e o faz com entusiasmo, dedicação, necessidade de auto realização, entre outros. Todos os entrevistaram validaram essa teoria:

Começando por A.F:

"Por ser minha profissão, né, por eu ser professor de educação física e minha família também. Hoje em dia meus filhos também são professores de educação física e é nosso ramo, o esporte e eu acredito muito no esporte como ferramenta pro veículo social. "

E.N corrobora essa teoria de maneira mais simples:

"Há muito tempo eu fui jogador de futebol e sempre tive o sonho de poder dar aula. Agora, eu dei o 
primeiro passo eu me sinto satisfeito, mas em busca de crescer meu negócio no futuro. "

A.R também valida a teoria:

"Eu sempre tive vontade de ter um negócio próprio, né, e pude aliar isso com um esporte que eu amo que eu sempre pratiquei de forma amadora, podendo transformar isso também em escolinha e como uma prática de atividade física, é um mercado novo dentro da educação física, a gente não vende só a performance futevôlei, a gente vende a atividade física futevôlei, isso é um grande nicho. “

Diferentemente, L.P limitou-se a dizer:

"A oportunidade surgiu. É o esporte que sempre pratiquei e que tenho certo nome. "

\subsection{Riscos e Erros}

Todos os entrevistados são os donos de seus empreendimentos, em alguns casos tendo outros sócios envolvidos no dia a dia, na tomada de decisão, divisão de lucros, por assumir risco, entre outras responsabilidades, segundo Leite (2000). Em relação ao maior erro já cometido por alguns de nossos entrevistados, podemos citar A.F:

"Meu principal erro, cara, foi participar de tudo sem muita escolha no início e tipo assim, eu nunca fui de engolir muito sapo e nessa modalidade (beach soccer) as vezes temos que engolir sapos e eu sempre fui muito Geração, sempre dei a vida pela minha família, pela minha classe. "

Citando outro erro, L.P:

"Nosso principal erro foi ter começado a escolinha sem material próprio, então teve um dia que não conseguimos o material que estávamos contando e tivemos que correr atrás desse material, porque a aula 
estava marcada, mas no final consegui o material e deu tudo certo."

Por fim, citando um erro de outra natureza, DC:

"O meu erro é não ter tanto tempo quanto eu gostaria. Como eu divido meu tempo com outras atividades, o negócio não está tão profissional quanto poderia, mas eu vou dar um jeito de arrumar mais tempo para isso."

O risco mais comum foi o de ter começado o negócio sem regularização junto a prefeitura ou pela falta de um certificado do CREF (Conselho Regional de Educação Física).

\subsection{Benefícios para a Sociedade}

Os empreendedores também são responsáveis por trazer benefícios para a sociedade, impactando de maneira positiva na sua comunidade, de acordo com o tamanho do empreendimento, conforme Oliveira (2004). Os entrevistados, em sua maioria, citaram a questão da saúde, desenvolvimento pessoal (socialização), criação de laços (amizade e carinho) com a comunidade e de habilidades adquiridas com a prática do esporte, validando a teoria utilizada ao longo deste trabalho, entretanto, uma resposta chamou a atenção por atingir o objetivo de impactar a sociedade, conforme a teoria de Vieira (2001).

Segundo P.A:

"O meu foco nisso é tirar essa garotada desses focos ruins, que são bailes (funks), tem gente que vai pra curtir, mas tem muita coisa errada também que acaba envolvendo essa geração que tá de mal a pior, a aprender coisas erradas, então eu tento trazer eles $e$ passar outras coisas sobre esporte e sobre a vida, porque eu também não consigo falar só de esporte. Eu 
falo muito sobre Deus e tenho muito orgulho de ser a pessoa que passa essas coisas pra eles. “

\subsection{Inspiração}

$\mathrm{Na}$ entrevista uma pergunta busca informações sobre o mérito de referência (inspiração) para a criação desse negócio, mesmo que essa referência tenha seu negócio em outra área, ou que seja um incentivador. A maioria dos entrevistados validou a teoria de que o empreendedor tem inspirações para abrir seu negócio. As respostas foram variadas, A.F surpreendentemente deu a seguinte resposta:

"Não tenho referência anterior a mim. Eu joguei bola. Sempre fui apaixonado por futebol, sempre fui apaixonado por bola e meu primeiro filho, menino, eu falei: "é, vou montar uma escolinha de futebol, minha profissão. “...e caímos pra dentro. “

P.A também segue pela linha familiar:

"Minha única inspiração e herói pra minha vida é o meu pai. Ele é meu avô mas eu considero ele como pai, ele me criou desde pequenininho, sempre foi meu maior incentivador, em tudo e como eu disse, assim que eu tive a ideia eu conversei com meu pai e ele me apoiou e me passou tudo que poderia acontecer e se eu estava disposto a correr atrás de toda a documentação e fazer acontecer. "

Mais um exemplo de familiar que inspirou um dos entrevistados, L.P:

"Eu me inspirei no meu pai. Ele é dono de empresa. "

Fugindo do padrão, D.C teve outra resposta:

"Não tenho ninguém na família, a inspiração foram dois amigos, eles queriam fazer um encontro para aprender a jogar futevôlei, com uma ex-namorada minha 
e uma grande amiga minha também, aí juntou mais um amigo meu e juntaram os 4. E assim começou. "

Com um outro tipo de resposta, A.R:

"Não tive inspiração de ninguém."

Por fim, P.P:

"Minha inspiração fui eu mesmo. Cheguei a ser jogador profissional, mas acabei largando por motivos pessoais, então a partir desse projeto posso ajudar, a partir da minha experiência, que outras crianças e adolescentes consigam atingir esse objetivo. "

De maneira geral, foi possível observar alguns padrões de inspirações, apesar da pequena amostragem. Os mais recorrentes foram: família, experiência própria, amigos e por fim, ninguém.

\subsection{Desafios}

O empreendedor lida com desafios diariamente, segundo autores utilizados ao longo desse trabalho. Uma das características do empreendedor é a forma como ele supera esses desafios a fim de manter seu negócio, sobretudo no início conforme Sobral (2008). Os entrevistados falaram sobre suas maiores dificuldades, a maioria com dificuldades burocráticas junto a prefeitura, tendo ainda aqueles que ainda não possuem essa regularização. Exemplificado por P.A:

"Ainda estou correndo atrás de regularização.

Em outro caso, R.G, que não é do Rio, citou o seguinte:

"Minha maior dificuldade foi por eu não ser do Rio. No começo não tinha alunos e tive que correr atrás para provar que eu era capacitado para ensinar. $O$ negócio ainda está pequeno, mas começa a fluir. “

Em outros casos, como o de A.F, o maior empecilho foi financeiro:

"Foi a capacitação (captação) de recursos, a gente procurou muito, assim, mas com o trabalho tudo aparece. De repente, começou a chover patrocinadores, 
iniciativa privada né, começaram a apoiar e tivemos um patrocínio que foi o alicerce e estamos juntos até hoje. “

Dentre as maiores dificuldades encontradas hoje, as três maiores foram: maior profissionalização, regularização e diferenciação do serviço. Independente disso, todos continuam tocando seus negócios.

\subsection{Modelo de Negócios}

Como visto no tópico 2.2, os empreendedores costumam utilizar modelos de negócios que auxiliam na criação, implementação e para manter o negócio. Literalmente, nenhum dos entrevistados apresentou um modelo de negócio, tampouco conhecem o modelo BMG - Canvas, criado por Osterwalder (2011), possivelmente possuem algum por mais amador que seja, mas não forneceram essa informação ou não souberam responder. Em relação às tecnologias utilizadas, a maioria citou internet e redes sociais. Apenas dois destoaram, conforme diz A.F:

"Utilizamos métricas de análise de desempenho de nossos atletas e dos adversários. "

Para outros fins, A.R:

"Utilizamos o aplicativo Tecnofit (mensuração de resultados dos alunos e pagamentos das mensalidades). A partir dele, conseguimos acompanhar a evolução individual de cada aluno e traçar metas. “

Assim sendo, podemos concluir que apesar do empreendedorismo ter uma forte ligação com a tecnologia, nesse segmento, não encontramos muitas ferramentas tecnológicas que auxiliem o trabalho do dia a dia, a não ser nos casos citados acima.

\subsubsection{BMG - Canvas}

Conforme visto no tópico 2.2, um modelo de negócios, segundo (OSTERWALDER, 2011), pode ser composto por 9 fatores. Ao longo da pesquisa foi possível identificar esses itens:

1) Segmento de Clientes por A.F:

"Inicialmente, nosso público alvo eram crianças das classes $A$ e $B$. Hoje em dia, recebemos apoio do governo do estado e trabalhamos 
majoritariamente com crianças de todas as comunidades (favelas), visando sempre competições. "

Ainda pela linha social, P.A:

"Meu público alvo são crianças dos morros do Tabajara, Pavão Pavãozinho e Chapéu Mangueira. “

Por outro lado, D.L cita um outro tipo de público:

"Nosso público vem aqui visando um esporte e não competição. A maioria vem aqui para praticar exercício com foco na saúde. Clientes das classes $C$ e B. “

Outro perfil de cliente é o alvo de L.P:

"Meu perfil de cliente são pessoas mais velhas, todas iniciantes. Clientes das classes $C$ e $B$. “

Por fim, o último perfil de cliente observado, por A.R:

"Temos clientes de todas as categorias. Do iniciante ao avançado, que disputa competições. São clientes das classes $C$ a $A$. “

Apesar de traços em comum é possível observar algumas diferenças de perfis de clientes dos entrevistados. Variam de iniciantes (maioria) à competidores, das classes $\mathrm{D}$ até a $\mathrm{A}$ e a característica mais comum é a de procurarem um estilo de vida mais saudável.

2) Proposta de valor: a maioria dos entrevistados citou fatores bastante comuns (saúde, qualidade de vida, relacionamento e impacto social) entre os negócios. Entretanto, alguns entrevistaram abordaram outros valores, a seguir a resposta de J.G para essa questão:

"Aqui no CT (centro de treinamento), o diferencial é o foco em competições, independentemente do nível do atleta. "

D.C também apresentou uma proposta de valor diferente:

"Aqui abrimos as portas para todos, inclusive pessoas especiais."

E por fim, A.R:

“Uma maior variedade de planos (mensais, trimestrais, semestrais e anuais). Agora estamos investindo em produtos como camisas. Faremos um campeonato onde os alunos ganharão uniformes que 
serão usados durante as aulas, para conceituarmos o uso constante do uniforme. "

3) Canais utilizados pelos empreendedores para a divulgação são o boca a boca, e para a entrega do serviço normalmente a praia ou áreas ao ar livres, as respostas foram as mesmas, como afirma A.R:

"A maioria vem porque existe muito boca a boca, fora que nossa aula é na praia, muitas pessoas passam pelo calçadão e perguntam sobre a escolinha. “

P.P complementa:

"As pessoas passam aqui e veem. Além das redes sociais, principalmente o Instagram e dos próprios alunos que fazem essa divulgação entre amigos. "

4) Relacionamento com clientes também foi possível obter padrões de respostas, focando no clima familiar existente nas escolinhas, como afirma P.P:

"Aqui temos uma relação próxima com todos os alunos. Todos têm abertura para conversar com a equipe e são tratados de igual para igual. "

E.N limitou-se a dizer:

$$
\text { "Aqui somos todos amigos." }
$$

5) Nas fontes de receita, a maioria dos entrevistados deram a mesma resposta: mensalidades. Entretanto, com algumas variações, conforme diz A.F:

"Todos os profissionais aqui são pagos pelo Governo do Estado, nós temos patrocínio da Secretaria do Esporte. “

P.A cita como sua renda varia de aluno para aluno e consequentemente de mês para mês:

"Como trabalhamos com crianças de comunidade, as vezes a renda varia, temos alunos que não tem condições de pagar, mas mesmo assim mantemos eles aqui, porque o foco é também o lado social. "

6) Recursos principais: a pesquisa resultou, mais uma vez, em padrões de resposta, visto que, por serem esportes coletivos e praticados no mesmo ambiente (praia), utilizam basicamente os mesmos recursos, sendo eles: bolas, coletes, redes, cones, além dos custos com funcionários. Para o futevôlei, uma variação, conforme A.R: 
"Custo de manutenção e montagem da bomba (de água, para molhar a quadra), principalmente no verão e a gasolina dessa bomba. “

7) Atividades chave: por se tratar de esportes amadores, ainda não há profissionalização de grande parte dos envolvidos, embora haja professores formados em Ed. Física e outros em formação. A partir disso, as atividades chave limitam-se as aulas e o bom relacionamento interpessoal dos professores para com os alunos. Conforme diz R.G:

"Acredito que além de uma estrutura mínima e materiais de qualidade o mais importante é saber lidar com os alunos e passar para eles de maneira personalizada o nosso conhecimento. “

Seguindo por essa linha, P.P:

"O serviço é simples, mas requer uma abordagem diferente para cada aluno, sei porque tive dificuldades que outros não tiveram e vice e versa. "

A.F aumenta o leque de atividades:

"É um esporte amador, então os próprios meninos trazem suas águas. $E$ as atividades, nós trabalhamos o voleibol, futebol de 11 e o beach soccer. $E$ os materiais.

8) Principais parceiros: por se tratar de esportes amadores, a maioria dos entrevistados não possui parcerias, somente os três a seguir, começando por A.F:

"Nosso maior parceiro é o governo do estado.

P.A encontrou parcerias com uma outra instituição, o Botafogo Beach Soccer:

"Temos uma parceria com o beach soccer do Botafogo. Hoje nossa escolinha se chama Energia Praia Esporte, mas com apoio do Botafogo. Trabalho com crianças, mas que mais pra frente são selecionadas por eles e podem "subir" de categoria. Em troca eles fornecem o material para a aula. “

A.R também citou uma parceria:

"Por enquanto só a Atytude Futevolei. “ 


\section{Conclusão}

O esporte amador de fato ainda precisa evoluir muito no quesito de organização e investimentos até se tornar um negócio rentável que de fato possa ser uma atividade que sustente os empreendedores. Entretanto, levando em consideração os autores citados ao longo do documento, como Dolabela, Dornelas, Schumpeter, Menezes, Sebrae, Leite e Kitzner os empreendimentos estudados apresentam características semelhantes aos apresentados no capítulo 2 (Empreendedorismo 2.1, Empreendedorismo no esporte 2.1.1, Empreendedorismo social 2.1.2). Dentre essas características, destacam-se a criação de valor, melhora a relação do homem com os outros e promovem a destruição criativa, além de gerar inovação nos negócios já existentes.

Em relação ao perfil do empreendedor, a pesquisa validou as teorias utilizadas ao longo do estudo, tendo os entrevistados características em comum, como a criatividade, a necessidade de auto realização, assumem riscos, eliminam barreiras, geram benefícios econômicos e sociais e a atitude. Além disso, foi concluído que todos os entrevistados abriram seus negócios por oportunidade. O estudo observou que nove dos entrevistados são do gênero masculino e apenas uma é do gênero feminino, traçando assim um perfil que condiz com alguns valores enraizados no contexto sociocultural do Brasil. Além disso, as idades variam de 21 a 63 anos, estando a maioria na faixa etária de 24 a 32 anos.

A maioria dos entrevistados revelou falta de planejamento inicial e desconhecimento de algumas ferramentas como o BMG - Canvas. Todavia, possuem seus planejamentos, em sua maioria a curto prazo, excetuando-se os dois entrevistados mais velhos, A.R e A.F, que possuem seus negócios mais desenvolvidos e com visões de mais longo prazo. Conclui-se que, majoritariamente os empreendedores mais novos ainda buscam a consolidação de seus negócios, o que justifica o planejamento de curto prazo. As maiores dificuldades encontradas entre os entrevistados foram a legalização e alvará, diferenciação do serviço e captação de recursos pré e pós criação do negócio.

A pesquisa revelou que esse tipo de empreendedorismo também traz impactos sociais não só para os clientes, mas também para a sociedade em si, a partir 
do momento em que se busca transformar o contexto em que alguns agentes estão inseridos (criminalidade), combatendo a marginalização dos mesmos.

Os negócios apresentam desafios semelhantes entre si, como a informalidade. Quanto aos 8 fatores do BMG - Canvas de Osterwalder (2011), a maioria dos empreendimentos também apresentam segmentos de clientes, propostas de valor, canais, atividades chave, relacionamento com clientes, fontes de receita, recursos principais e parceiros-chave parecidos, o que os tornam concorrentes.

A pesquisa mostrou que os esportes amadores ainda precisam de um olhar mais profissional para se tornarem rentáveis, além disso, o grau de inovação é um fator a ser levado em consideração, já que por terem baixas barreiras de entrada facilita o aumento da concorrência e, para captar mais clientes, o negócio deve se diferenciar dos demais.

Recomenda-se para estudos futuros um enfoque maior em empreendedorismo no esporte, sobretudo na esfera amadora e maneiras de diferenciar esse tipo de negócio, principalmente por sua baixa barreira de entrada, o que facilita a concorrência, mas ainda com propostas de valor muito semelhantes. Além disso, seria interessante um estudo específico a respeito de que tipo de inspirações o empreendedor tem para abrir seu negócio, na presente pesquisa a resposta mais comum foi inspiração familiar, porém, como dito anteriormente, trata-se de uma amostragem pequena. 


\section{Bibliografia}

AZEVEDO, A. A. de. Dos velhos aos novos cartolas: uma interpretação do poder e das suas resistências nos clubes, face ao impacto das relações futebolempresa. Tese (Doutorado em Sociologia) - Instituto de Ciências Sociais, Universidade de Brasília, Brasília, 1999.

BRITTO, F; WEVER, L. Empreendedores brasileiros: vivendo e aprendendo com grandes nomes. Rio de Janeiro: Campus, 2003.

CBN, Rádio Globo. Rio é o estado com o menor número de praticantes de esportes do país https://cbn.globoradio.globo.com/editorias/cienciasaude/2017/05/17/RIO-E-O-ESTADO-COM-O-MENOR-NUMERO-DE-

PRATICANTES-DE-ESPORTES-DO-PAIS.htm Acesso em: 20/04/2019.

COSTA, L. P. da. (org). Atlas do esporte no Brasil: atlas do esporte, educação física e atividades físicas de saúde e lazer no Brasil. Rio de Janeiro: Shape, 2005. 923p.

COSTA, L. P. da. (org). Atlas do esporte no Brasil: atlas do esporte, educação física e atividades físicas de saúde e lazer no Brasil. Rio de Janeiro: Shape, 2005. $760 \mathrm{p}$.

DE MORI. F. (Org.). Empreender: identificando, avaliando e planejando um novo negócio. Florianópolis: Escola de Novos Empreendedores, 1998.

de Tenis Paulista, Federação. https://www.tenispaulista.com.br/beach-tennis/ Acesso em: 25/04/2019.

DOLABELLA, F. O segredo de Luisa. Rio de Janeiro: Sextante, 2008.

DORNELAS, J. C. A. Empreendedorismo: transformando ideias em negócios. Rio de Janeiro: Elsevier, 2001.

DORNELAS, J.C.A., Empreendedorismo: Transformando Idéias em Negócios. $2^{2}$ Ed. - Rio de Janeiro: Campus, 2005.

DORNELAS, José Carlos Assis. Empreendedorismo Corporativo. São Paulo: Editora Campus, 2003.

DORNELAS, José Carlos Assis. Empreendedorismo. São Paulo: Editora Elsevier Brasil, 2008. 
DORNELAS, José. Empreendedorismo: Transformando ideias em negócios. 4. ed. Rio de Janeiro: Elsevier, 2012.

DORNELAS, José. Empreendedorismo: Transformando ideias em negócios. 5. ed. Rio de Janeiro: Empreende/LTC, 2014.

FEUERSCHÜTTE, S. G. \& GODOI, C. K. Competências empreendedoras: um estudo historiográfico no setor hoteleiro. In: XXXI EnANPAD - ENCONTRO NACIONAL DOS PROGRAMAS DE PÓS-GRADUAÇÃO EM ADMINISTRAÇÃO. Anais eletrônicos. Rio de Janeiro: ANPAD, 2007.

Gamesbras. "A meta é dobrar o número de adeptos do poker nos próximos três anos" https://www.gamesbras.com/poker/2017/12/12/meta-dobrar-numero-adeptospoker-proximos-trs-anos-5890.html Acesso em 27/04/2019.

Gamesbras. Poker está cada vez mais popular no Brasil https://www.gamesbras.com/poker/2019/1/31/poker-esta-cada-vez-mais-popular-nobrasil-11405.html Acesso em 27/04/2019.

GAYA, A. Sobre o esporte para crianças e jovens. In: STIGGER, M.P.; LOVISOLO, H.R. (Orgs.) Esporte de rendimento e esporte na escola. Campinas: Autores Associados, 2009.

GIL, Antonio Carlos. Como Elaborar Projetos de Pesquisa. São Paulo. Editora Atlas S.A., 2002.

GIL, Antonio Carlos. Métodos e técnicas de pesquisa social, Atlas, 2008.

GRAÇA FILHO, A.S.; KASZNAR, I.K. O esporte como indústria: solução para a criação de riqueza e emprego. Rio de Janeiro: Confederação Brasileira de Voleibol, 2002.

HISRICH, R. D., \& Peter, M. P. Empreendedorismo. Porto Alegre: Bookman, 2004.

HUEFNER. Jonathan. C; HUNT, H. Keith; ROBINSON, Peter. B. A comparison of four scales predicting entrepreneurship. Academy of Entrepreneurship Journal, v. 1, n. 2, p. 56-80, Fall 1996.

Kirzner, I. M. (1973). Competition and entrepreneurship. Chicago: University of Chicago Press.

Lance!, O. Prova de ciclismo reúne mil atletas amadores no Rio de Janeiro https://www.lance.com.br/mais-esportes/prova-ciclismo-reune-mil-atletas-amadoresrio-janeiro.html Acesso em 27/04/2019.

LEITE, E. O Fenômeno do Empreendedorismo. Recife: Bagaço, 2000. 
MENEZES, L.C.M. Gestão de Projetos. 2 ed. São Paulo: Atlas, 2003

OLIVEIRA, Edson Marques. Empreendedorismo social no Brasil: atual configuração, perspectivas e desafios. Revista da FAE, Curitiba, v.7, n. 2, p. 9-18, jul.-dez. 2004.

OLIVEIRA, Edson Marques. Empreendedorismo Social no Brasil: fundamentos e estratégias. 2004. Tese (Doutorado) Universidade Estadual Paulista - Unesp, Franca, 2004.

OSTERWALDER, Alexander, PIGNEUR, Yves. Business Model Canvas - Inovação em Modelos de Negócios. Um Manual para Visionários, Inovadores e Revolucionários. Rio de Janeiro: Alta Books, 2011

PAIVA, F. G., Jr., Leão, A. L. M. S., \& Mello, S. C. B. (2003, setembro). Competências empreendedoras em comportamentos de dirigentes de êxito socialmente reconhecido. Anais do Encontro Nacional da Associação Nacional de Pós-Graduação e Pesquisa em Administração, Atibaia, SP, Brasil.

Pegn, Revista. Empreendedorismo atrai 52 milhões de brasileiros em 2018 https://revistapegn.globo.com/Empreendedorismo/noticia/2019/02/empreendedorism o-atrai-52-milhoes-de-brasileiros-em-2018.html Acesso em 15/05/2019.

RIBEIRO, Elisa. A perspectiva da entrevista na investigação qualitativa. 2008.

ROSA, M.V.F.C E ARNOLDI, M.A.G. A entrevista na pesquisa qualitativa: mecanismos para a validação dos resultados. Autêntica Editora, 2006.

SCHUMPETER, Joseph. Capitalismo, Socialismo e Democracia. Editora Claridad, 1946.

SCHUMPETER, Joseph. Teoria do Desenvolvimento Econômico. Editora Abril Cultural, 1982.

SEBRAE. Conheça as características empreendedoras desenvolvidas no Empretec http://www.sebrae.com.br/sites/PortalSebrae/Programas/conheca-ascaracteristicas-empreendedoras-desenvolvidas-no-

empretec,d071a5d3902e2410VgnVCM100000b272010aRCRD Acesso em $15 / 06 / 2019$

SEBRAE. DISCIPLINA DE EMPREENDEDORISMO. https://bibliotecas.sebrae.com.br/chronus/ARQUIVOS CHRONUS/bds/bds.nsf/Ofccfa 389a947eaa06f8164abe215777/\$File/5695.pdf Acesso em 25/05/2019.

SOBRAL, F.; PECI, A. Administração: teoria e prática no contexto brasileiro. São Paulo: Prentice Hall, 2008.

SWOBODA, P. Schumpeter's Entrepreneur in Modern Economic Theory. Lectures on Schumpeterian Economics, New York: Springer-Verlag, 1983. 
TUBINO, M. J. G. Teoria geral do esporte. São Paulo: IBRASA, 1987. 80p.

UOL. Nova academia? Futevôlei amplia público e quadras para crescer em São Paulo https://esporte.uol.com.br/ultimas-noticias/2018/11/21/nova-academiafutevolei-amplia-publico-e-quadras-para-crescer-em-sao-paulo.htm Acesso em 25/04/2019.

VESPER, Karl H; GARTNER, William B. Measuring progress in entrepreneurship education. Journal of Business Venturing, v. 12, p. 403-21, 1997. 


\section{Apêndice 1 - Roteiro das Entrevistas}

1. Como surgiu a ideia de empreender no esporte amador?

2. Por que você decidiu empreender? Por que nesse ramo?

3. Quem administra os negócios no dia a dia?

4. Qual foi seu principal erro até agora? Como você resolveu esta questão? Como se sentiu?

5. Qual sua maior motivação? (Sem ser financeira)

6. Qual o benefício que seu negócio traz para os praticantes / clientes e para a sociedade?

7. Em quem se inspirou para empreender? Há alguém na família que empreende?

8. Como identificou a oportunidade para empreender no esporte amador? De quando teve a ideia para o momento de implantação do projeto, quanto tempo levou?

9. Qual foi o seu maior desafio para iniciar o empreendimento e qual o seu maior desafio hoje?

10. Você possui equipe? Como garante/monitora o resultado da equipe?

11. Você usa tecnologia de alguma forma em seu serviço? COMO? QUAL?

12. Você conhece o conceito lean e BMG ou usou alguma ferramenta (plano de negócios/canvas) para estruturar seu negócio? Qual?

13. Você realiza planejamento e define objetivos específicos e metas periódicas?

14. Qual o perfil do seu cliente? Como você identificou este perfil?

15. Qual o diferencial competitivo? Qual a proposta de valor do seu negócio (caso o entrevistado conheça as metodologias)?

16. Quais os seus maiores custos?

17. Quais suas fontes de receitas? De que forma você consegue tornar seu negócio rentável?

18. Como você entrega seu produto ou serviço ao cliente? (Canais) 
19. Como você mantém seu relacionamento próximo com o cliente? (Relacionamento)

20. Quais são as principais atividades e recursos que necessita no dia a dia do negócio?

21. Quem são seus principais parceiros? 